\title{
Para além do sucesso técnico: rede sociotécnica em pequenas comunidades rurais amazônicas, Amazonas- Brasil
}

\section{Besides technical success: socio-technical network in small rural communities of the Brazilian Amazon}

Ana Claudeise Nascimento - Doutora em Sociologia pelo PPGSA/ UFPA. Pesquisadora do Instituto de Desenvolvimento Sustentável Mamirauá - OS/MCT. Email: claudeise@ mamiraua.org.br

Edila Arnaud Ferreira Moura - Doutora em desenvolvimento socioambiental pelo NAEA/ UFPA. Docente da UFPA atuando na graduação e no Programa de pós-graduação em Sociologia e Antropologia/PPGSA/IFCH. Email: eafmoura@gmail.com

Maria José da Silva Aquino Teisserenc - Doutora em Sociologia pelo PPGSA/UFRJ. Docente da UFPA atuando na graduação e no Programa de pós-graduação em Sociologia e Antropologia/PPGSA/IFCH. Email:mjaq@uol.com.br

\section{Resumo}

Este artigo tem como objetivo analisar a constituição de uma rede sociotécnica para desenvolver um melhor uso da água para o consumo humano e tarefas domésticas em pequenos agrupamentos populacionais $\mathrm{da}$ floresta alagada amazônica. O estudo toma por orientação a experiência empírica das pesquisadoras que atuam como agentes de programas de desenvolvimento sustentável em uma unidade de conservação de uso sustentável, há mais de 25 anos, e, os recursos analíticos da sociologia da tradução que contrapõe-se à ideia de uma separação entre social, tecnologia e ciência e, fundamentalmente, instiga a pensar o papel do ator na invenção. O estudo conclui que a produção científica e tecnológica precisa ser melhor compreendida nos seus processos e formas de alcance em relação às populações que se distanciam dos interesses dos mercados tecnológicos.

\section{Palavras-chave}

Rede Sociotécnica, Energias Alternativas, Tecnologia Social, Unidades de Conservação, Populações Ribeirinhas.

\begin{abstract}
This article aims to analyze the formation of a socio-technical network to develop a better use of water for human consumption and in household chores in small population groups in the Amazon flooded forest. The study takes as orientation the empirical experience of researchers who have worked as agents of sustainable development programs in a conservation unit of sustainable use for more than 25 years, and the analytical resources of sociology of translation that opposes the idea of a separation between the social, technology and science, basically inducing to think about the player's role in the invention. The study concludes that scientific production and technology need to be better understood in their processes and forms of achievement in relation to populations far from interests of the technological markets.
\end{abstract}

\section{Keywords}

Socio-technical Network, Alternative Energies, Social Technology, Conservation Units, Riverine Population. 


\section{INTRODUÇÃO}

As diversas expressões dos movimentos socioambientalistas que se destacaram no Brasil a partir do final do século passado, em especial aquelas que problematizaram os grandes riscos de perda da sociobiodiversidade amazônica, colocaram em evidência, no campo acadêmico e não acadêmico, as profundas assimetrias nas relações entre ciência, tecnologia e saberes locais relacionados às formas de organização da vida nos pequenos agrupamentos populacionais que ocupam as margens dos rios e outros corpos d’água, no amplo território da várzea (floresta alagada) amazônica. As consequentes ações políticas, em suas múltiplas manifestações, que vem se construindo sob o que se convencionou denominar de "desenvolvimento sustentável" tem evidenciado, mais intensamente, as questões relativas aos usos sociais da ciência e a constituição dos campos científicos (BOURDIEU, 1997) no conjunto das relações sociotécnicas (CALLON, LASCOUMES e BARTHE, 2011) onde se destacam as complexas redes de produção e de uso do conhecimento, na configuração de fóruns híbridos (CALLON, LASCOUMES e BARTHE, 2011), no alcance das soluções que requerem abordagens multidisciplinares.

Como largamente reconhecido, a qualidade de nossas respostas depende da qualidade de nossas perguntas. E aqui, trazemos ao debate, na condição de pesquisadoras e agentes sociambientais vinculadas ao Instituto de Desenvolvimento Sustentável Mamirauá - IDSM ${ }^{1}$, nossas experiências de atuação em uma ampla rede sociotécnica que se compõe há mais de vinte anos e que se estende entre vários territórios sociais no propósito de contribuir com inovações sociais para "melhor viver" em um ambiente onde os pulsos de inundação da água imprimem dinâmicas que se refletem na alteração da paisagem, nos ritmos da vida e na intensidade dos seus riscos e incertezas (JUNK, 2000; PORRO, 1995; MOURA, 2007).

Nossa questão central, neste artigo, se orienta para a compreensão dos diversos mecanismos em disputa na tentativa de produzir construções técnicas e sociais - inovações sociais - para proporcionar um melhor uso da água para o consumo humano e tarefas domésticas nas moradias de pequenos agrupamentos populacionais, que se autoreferenciam como comunidades, territorializados ao

O Instituto de Desenvolvimento Sustentável Mamirauá-IDSM, criado em 1999, é uma instituição de pesquisa qualificada como organização social em parceria com o Ministério da Ciência, Tecnologia, Inovações e Comunicações-MCTIC, do governo federal brasileiro, que se consolidou após uma trajetória como organização não governamental - Projeto Mamirauá e Sociedade Civil Mamirauá e que hoje agrega mais de 200 pesquisadores e extensionistas produzindo pesquisas e desenvolvendo projetos de inovação social em unidades de conservação de uso sustentável na Amazônia. www.mamiraua.org.br 
longo dos caudalosos e intrincados rios amazônicos e que, por isso, são também identificados como populações ribeirinhas. Formulamos essa questão a partir das análises orientadas pela sociologia da tradução (CALLON, LASCOUMES e BARTHE, 2011) que traz, como principal contribuição, a reflexão sobre os processos de descoberta e inovação científica e tecnológica atentando para o protagonismo dos não-humanos no processo de produção da ciência, aos processos de constituição do saber, assim como aos mecanismos de atribuição do coletivo relacionando os avanços da ciência às avaliações e demandas da sociedade no exercício da democracia técnica.

Segundo Machado e Teixeira (2005), os sociólogos da tradução (Callon, 1986; 1989; 1995; Law, 2002) questionam a sobre-determinação do social no processo de produção da ciência ressaltando que a ausência ou presença de materiais, equipamentos e instrumentos de manipulação de dados produzem, alteram e interditam estratégias de pesquisa. Ainda, segundo esses autores, duas exigências se impõem para os sociólogos da tradução. A primeira, é dar peso ao trabalho de representação dos não-humanos (coletivos). A segunda, é que o relativismo do sociólogo deve ser extensivo à sociedade. Os sociólogos devem também estar atentos às múltiplas interpretações da sociedade, dos atores e de seus interesses. A sociologia da tradução contrapõe-se à ideia de uma origem da inovação, à separação entre social, tecnologia e ciência e, fundamentalmente, instiga a pensar o papel do ator na invenção.

A pertinência dessa reflexão, que se expandiu da Inglaterra aos Institutos Cientificos Franceses e aos demais centros de pesquisa, se justifica neste estudo no sentido de que nos impulsiona a problematizar como esses processos ocorrem em sociedades com menor alcance na prioridade das pesquisas tecnológicas e sociais e em suas formas de intervenção. Nessa composição analítica, acrescentamos ainda os dados de estudos empíricos que realizamos no IDSM sobre os processos inovadores direcionados aos pequenos agrupamentos populacionais da floresta alagada amazônica, sob os parâmetros das políticas de conservação ambiental e das diretrizes de uma nova ciência mais comprometida com o desenvolvimento sustentável.

O IDSM é uma instituição de pesquisa vinculada ao Ministério da Ciência, Tecnologia, Inovações e Comunicações - MCTIC com sede na cidade de Tefé, principal centro econômico e político de uma área de floresta alagada, no estado do Amazonas, Brasil. Este instituto foi criado no ano de 1999, dez anos após o reconhecimento da primeira unidade de conservação de uso sustentável (SNUC, 2000) no Brasil e na sequência às movimentações socioambientais expressivas desse momento da história amazônica que envolveram várias organizações 
governamentais e não governamentais (MOURA, 2007). Ao longo desses anos, o IDSM agencia pesquisas sobre a sociodiversidade amazônica como também impulsiona inovações sociotécnicas com uma variada composição de atores sociais (www.mamiraua.org.br). Em sua trajetória institucional podemos identificar práticas que se relacionam com o que Callon, Lascoumes e Barthe denominam de interseções entre a Recherche confinée e recherche de plein air (CALLON, LASCOUMES e BARTHE, 2011) que expressam as diversas formas de lidar com as incertezas que, de forma paradoxal, se intensificam no mundo contemporâneo e se evidenciaram ainda mais no percurso dos recentes estudos ambientais. Ao tomar o IDSM como um objeto de reflexão exercitamos também o entendimento de Callon e sua equipe sobre os Foruns Híbridos, categoria de análise proposta por esses autores para analisar as controvérsias que ocorrem em espaços públicos envolvendo diversos atores e interesses da sociedade (CALLON, LASCOUMES e BARTHE, 2011). Para este estudo, recorremos a uma, dentre as várias inovações sociais desencadeadas por este Instituto.

No desenvolver do artigo apresentamos a análise distribuída da seguinte forma: caracterização da situação-problema e as bases para o processo da tradução, composição da relação sociotécnica em relação às características e demandas das populações e reflexões sobre os mecanismos de disputa e o alcance das expectativas geradas ao longo de mais de 25 anos do processo dessa inovação. Com esta análise compartilhamos e intendemos avançar, a partir dos sociólogos da tradução, a expectativa de que a produção científica e tecnológica precisa ser melhor compreendida nos seus processos e formas de alcance em relação às populações que se distanciam dos interesses dos mercados tecnológicos.

\section{A SITUAÇÃO-PROBLEMA E O PROCESSO DA TRADUÇÃO: O MODO DE VIDA NA VÁRZEA E OS USOS SOCIAIS DA ÁGUA}

\subsection{O MODO DE VIDA NA VÁRZEA E OS USOS SOCIAIS DA ÁGUA}

O IDSM concentra suas ações para as populações das reservas de desenvolvimento sustentável Mamirauá e Amanã, que correspondem a uma área de 3.474.000 hectares de florestas alagáveis (várzea e igapó) e terra firme, na região do Médio Solimões, estado do Amazonas. Esse território é reconhecido pelos estudos científicos como área de grande endemismo de espécies, variedade 
e abundância de pescado, recursos madeireiros e não madeireiros, um ambiente de floresta alagada (várzea) e áreas de terra firme, como característicos de outras paisagens ao longo dos rios Solimões/Amazonas ${ }^{2}$, mas com uma fascinante e expressiva sociobiodiversidade (AYRES, 1993; LIMA, 2005; ALENCAR, 2002 e 2010; MOURA, 2007). Nesse vasto território (Figura 1) estão distribuídos 212 pequenos povoados, variando de 4 a 35 moradias, localizados sempre a margem dos rios, paranás ou lagos, caracterizando, em toda essa extensão, uma população totalmente dependente dos cursos d'água para seu deslocamento a pequenas e a grandes distâncias, entre as áreas rurais assim como em direção às áreas urbanas. Em 2011, o total dessa população era de 9.532 pessoas, correspondendo a 0,27 habitantes por quilometro quadrado. Neste estudo, por razões que serão esclarecidas no decorrer deste tópico, a análise vai se direcionar aos habitantes da várzea da área da Reserva de Desenvolvimento Sustentável Mamirauá -RDSM.

Figura 1 - Mapa das Reservas de Desenvolvimento Sustentável Mamirauá e Amanã, Amazonas, Brasil

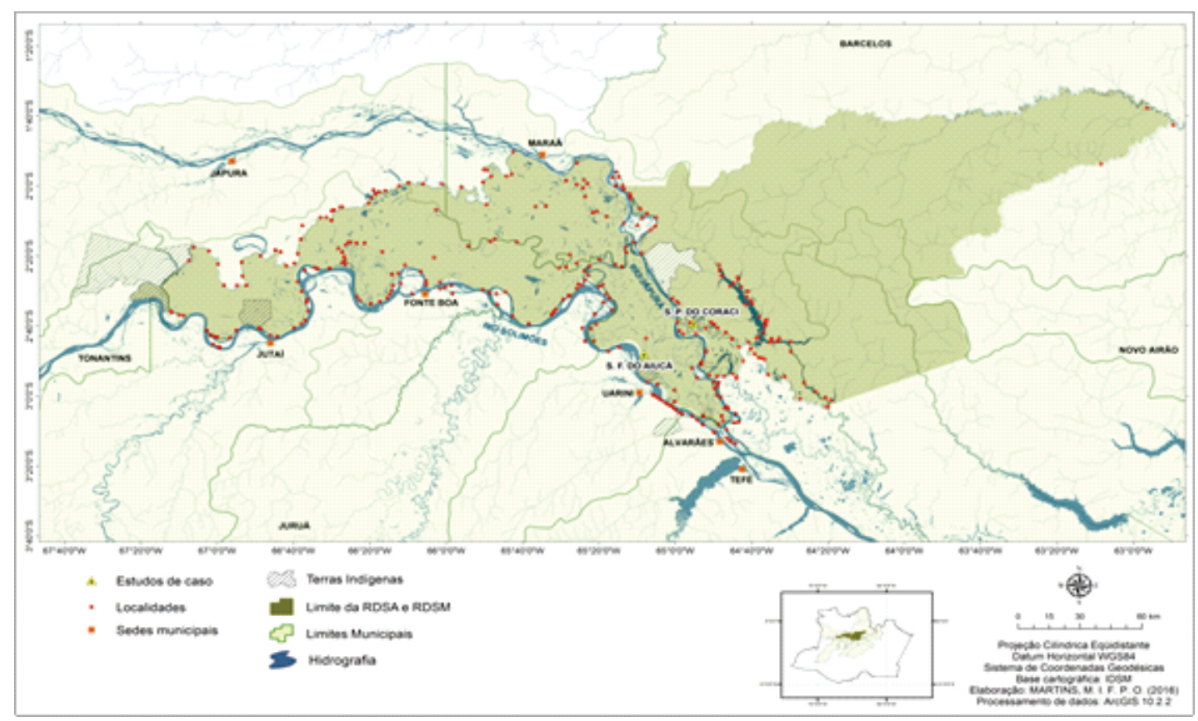

Fonte: Base Cartográfica IDSM. Martins, M. I. F. P. O, 2016

Segundo Lima (2005), estudar a população da várzea é conhecer os habitantes das margens baixas do rio com o maior volume de água do mundo. É também conhecer a região de colonização mais antiga da Amazônia (p.11). Forma

\footnotetext{
2 Segundo Lima (2005), ao longo dos $3.000 \mathrm{~km}$ de extensão dos rios Solimões/Amazonas, em terras brasileiras, ocorrem dois tipos de ambientes: a várzea, como é chamada a área de planície inundada anualmente, e a terra firme, terras altas que consistem em extensões do platô do periodo terciário que alcançam as bordas do rio. Esses dois tipos de ambiente se alternam ao longo das margens do rio, e neles moram populaçöes ribeirinhas que, embora vizinhas, apresentam modos de vida diferenciados (p. 11).
} 
de organização social que foi profundamente afetada pelos vários processos civilizatórios que, seja através da Igreja Católica ou através das políticas de Estado entre outras formas de dominação do território, ocorreram nessa região ao longo da história da formação da sociedade brasileira.

\subsubsection{A SAZONALIDADE DA VÁRZEA AMAZÔNICA³}

Na cheia "Está todo mundo de bubuia". Na seca "ficamos completamente isolados". Essas são referências dos moradores da várzea exemplificando aos momentos contrastantes em relação aos pulsos de inundação ao longo do ano, que compõem um calendário com os períodos de enchente (meados de novembro a início de maio), cheia (maio a meados de julho), vazante (final de julho a meados de setembro) e seca ( setembro a meados de novembro). A série de dados coletados, anualmente, pelo IDSM desde 1990 sobre a variação desses pulsos d'água na área da RDSM constata uma variação média de até 12 metros de elevação das águas entre os períodos de seca e cheia. Há ainda as imprevisíveis grandes cheias e grandes secas. Nas grandes cheias o nível das águas atinge mais de 15 metros acima do nível do mar, o que causa perdas na produção econômica, de equipamentos de trabalho, moradias e outros bens além da gravidade do registro de afogamentos de crianças. Nas grandes secas, ampliam-se as áreas isoladas, ocorrem perdas significativas na produção econômica como também na comercialização dos produtos. Por isso, como os moradores da várzea - os "varjeiros"- costumam dizer, morar na várzea é "estar sempre recomeçando" (MOURA, 2007).

Essa sazonalidade imprime variação nas fontes de renda, nos arranjos domiciliares, nas situações de risco, nas formas de sociabilidade. A enchente é o tempo da expectativa. Os ribeirinhos acompanham pelos programas de rádio as notícias sobre o nível da enchente na cidade de Tabatinga, rio Solimões acima, na fronteira com a Colômbia. E se preparam para o inevitável. Se a enchente prenunciar uma grande cheia é hora de acelerar a colheita da mandioca, preparar a farinha estendendo a jornada de trabalho doméstico por mais de 14 horas. É o tempo também de avaliar as condições para a extração da madeira nas áreas onde o manejo florestal comunitário está organizado (MOURA, 2007).

3 Neste item, e nos próximos dois, fazemos uma síntese da análise feita em MOURA, E. A F. Práticas socioambientais na Reserva de Desenvolvimento Sustentável Mamirauá. Tese (Doutorado em Desenvolvimento Sustentável do Trópico Úmido) - Núcleo de Altos Estudos Amazônico, Universidade Federal do Pará, Belém, 2007Capítulo 1, por a considerarmos bastante completa e ainda atual.

4 Expressão local que quer dizer estar flutuando na água. 
A cheia é o tempo de apreensão com a alagação. É o tempo de maior atenção com as crianças, que são muitas, de cuidado com os idosos, que dependendo da alagação tem que migrar para as casas de parentes na cidade. É o tempo também de proteger os animais, de grande e médio porte, nas marombas - gaiolas flutuantes para proteger o gado. Para os que não trabalham com gado nem com madeira, é também o tempo de descansar. "A gente sabe que o rio vai baixar... é só esperar". Se a cheia é grande, é tempo de reforçar as práticas de solidariedade, fornecendo o abrigo e trocando bens geralmente adquiridos com a renda das aposentadorias dos idosos, às vezes a única renda garantida nesse período. A pesca fica mais difícil com os peixes espalhados na profusão das águas. Os corpos d'água se fundem em um só corpo d'água, que, quando tranquilo, se assemelha a um grande espelho (MOURA, 2007).

A época da vazante é o tempo de avaliar as perdas com a cheia e novamente recomeçar. Reencontrar alguns dos objetos caídos n’água e que ficaram enterrados na lama que emerge com a descida das águas. Perdem-se equipamentos de trabalho, até motores rabeta. São grandes as perdas de pequenos animais e por isso muitos moradores preferem vendê-los quando se apresenta a expectativa de uma grande cheia. O consolo que todos sabem é que essa "benção das águas" fertiliza o solo com os nutrientes trazidos desde os Andes e traz a certeza do retorno do plantio em forma de alimento. É o tempo de organizar o replantio da roça, negociar a troca de sementes. Em algumas situações é preciso buscar sementes de terra firme porque a cheia levou tudo. É a época do surgimento das praias, da ameaça à predação dos quelônios, de se organizar para proteger a reprodução dos "bichos de casco". Na vazante, como na enchente, é também o tempo de apreensão com as terras caídas ${ }^{5}$, fenômeno natural que apavora os moradores por fazer submergir casas, canoas, barcos (MOURA, 2007). Esse fenônemo é também um dos responsáveis pela necessidade de deslocamento das famílias para outros lugares, uma forte característica da forma de ocupação na várzea. Estudos realizados com base em histórias orais, constataram que o tempo médio de permanência de um povoado em um mesmo lugar é de apenas 25 anos (LIMA e ALENCAR, 2000; ALENCAR, 2002; ALENCAR, 2010)

A seca é o tempo da fartura dos peixes nos lagos, dos moradores se organizarem para combater os "invasores" que colocam em risco a perda de um

\footnotetext{
5 "Terras caídas" ou desbarrancamento é um fenômeno natural da Amazônia. Causada pela erosão das margens de rios de águas barrentas. Esses rios, por terem fortes correntes, de pouca sedimentação, arrastam materiais nele contidos ou onde suas águas alcançam. Outro fator é a ação do vento e da chuva em margens desprotegidas de vegetação altas e rasteiras e/ou gramíneas. Também pode ser ocasionada pela dinâmica dos rios à procura de acomodação para seu leito, e pela degradação ambiental.
} 
ano ou mais de trabalho para preservar os lagos. É o tempo do maior esforço físico nas longas caminhadas em busca da água abaixo no barranco que surgiu em frente à comunidade, que pode atingir até mais de dez metros de altura, ou ir mata adentro na busca pelos igarapés e olhos d’água. É a época do espraiamento da paisagem, alongando a chegada aos rios, por onde passam os regatões ${ }^{6}$, com os comerciantes interessados nos produtos locais e na venda de mercadorias. É necessário caminhar na areia com o "rancho" nas costas, por mais de uma hora. É o tempo do isolamento em algumas comunidades pela total impossibilidade das pessoas se deslocarem a outros lugares (MOURA, 2007).

\subsubsection{O "CAMPESINATO DA VÁRZEA" E AS DEMANDAS DO "MERCADO ECOLÓGICO”}

Nesses ambientes de várzea da RDSM a vida social se reproduz com as características de uma organização social camponesa, em condições de acesso comum aos recursos naturais, fortemente definidos pela sazonalidade da variação do nível das águas. Esses aspectos socioambientais imprimem uma identidade a esse campesinato, no sentido de que se diferencia de outras situações na região Amazônica, que podemos lhe atribuir a denominação de "campesinato da várzeạ" (MOURA, 2007).

A organização produtiva é feita com base no trabalho da família como unidade doméstica de consumo e produção, avessa aos riscos das relações mercantis, limitada pela estrutura demográfica do grupo familiar - extenso e predominantemente jovem, fortemente afetada pelas imposições da sazonalidade dos recursos naturais, influenciada por relações com os mercados urbanos e pelas formas de atuação das políticas públicas nessa região. Essa organização produtiva é integrada a outros aspectos da vida social da localidade onde as relações pessoais são determinantes, definindo um modo de vida que diferencia um povoado do outro. As condições de acesso comum aos recursos naturais são estabelecidas pelas normas tradicionais de uso e apropriação dos recursos, onde as relações de parentesco são importantes atributos de pertencimento social. Mas, é pelo trabalho na natureza, como em outras organizações camponesas, que são demarcados os domínios entre os espaços usados em comum e os espaços usados privativamente pelas unidades familiares. Essas condições de trabalho são afetadas de formas diferenciadas pelas mudanças nas condições ambientais,

\footnotetext{
6 Barcos de pequeno porte que transitam frequentemente nos rios Solimões e Japurá e que praticam o comércio de produtos com as comunidades da reserva.

7 Rancho é como se referem aos itens adquiridos no mercado mais frequentemente.
} 
pelas ameaças de escassez dos recursos, pelas novas relações com o mercado que se compõem nas possibilidades trazidas com a modernização ecológica em curso desde a criação da reserva, que estimula a agregação de valores aos denominados produtos sustentáveis com inovações sociais de comprometimento com a convervação ambiental da várzea (MOURA, 2007).

Os produtores fazem o plantio logo que as águas começam a baixar e a colheita se inicia quando as águas começam a subir e se acelera com o ritmo de subida das águas. $\mathrm{Na}$ seca os moradores definem o plano de manejo comunitário dos recursos madeireiros, mas as árvores só serão cortadas quando o nível das águas atingir aquelas selecionadas para a comercialização nesse ano, pois as toras só podem ser transportadas pela via fluvial e só podem ser retiradas da floresta quando o nível da água permitir. Se fizerem a derrubada antes disso, os trabalhadores correm o risco de perder a madeira. $\mathrm{Na}$ seca a atividade mais intensa é a pesca, principalmente dos peixes de maior valor comercial como o pirarucu e o tambaqui. Para os moradores das localidades próximas aos lagos de maiores estoques, é esse período, cerca de dois meses, que garante $75 \%$ da sua renda monetária anual. Essa situação faz com que todos os esforços de trabalho possíveis sejam utilizados pelo grupo familiar para a atividade na pesca, assim como acontece na época da extração da madeira nas localidades onde essa extração é favorável. A época da cheia facilita o aumento da renda com a venda da madeira e em algumas áreas esta é a única fonte de renda para as famílias nesse período. A renda monetária familiar pode ser acrescida pelas aposentadorias rurais, pensões, a Bolsa Família, salários de professores e agentes de saúde e formas de assalariamento dos postos de trabalho de assistentes de pesquisa, fiscais, prestadores de serviços gerais na estrutura ocupacional criada pelo IDSM a partir de 1992. A atividade econômica predominante é a pesca, de lagos e de rios, conforme a época do ano e conforme os lugares. É da pesca que provem o alimento básico - o peixe, principalmente o bodó, complementado com a farinha de mandioca (MOURA, 2007).

Essa alternância dos fluxos da água, além de determinar as condições de acesso aos recursos altera também o ritmo de vida das pessoas que habitam esses lugares. $\mathrm{Na}$ cheia, o tempo de deslocamento entre as localidades e em direção aos centros urbanos fica menor. $\mathrm{Na}$ seca, o trajeto torna-se mais longo e perigoso. É preciso desenvolver habilidades para o trânsito fluvial, pois corre-se o risco de encalhar a embarcação nos bancos de areia que se formam com a descida das águas.

Até o início dos anos 1990 a produção econômica era feita predominantemente através do trabalho familiar, com relações mercantis com os "patrões" (regatões) e com o comércio dos centros urbanos, dependendo do tipo 
de produto e das oportunidades. Ainda é a forma predominante de produção econômica e de comercialização, porém, a partir de 1998 os produtores familiares, em algumas localidades, se relacionam também com outras formas de produção e comercialização no âmbito do mercado ecológico que ocorre com intermediações de vários atores numa ampla rede sociotécnica.

Para participar desse mercado os produtores locais recebem orientações para executar as atividades de produção e comercialização em acordo com as exigências dos compradores, com melhoria na qualidade e apresentação dos produtos, respeito à legislação ambiental e às normas estabelecidas no Plano de Manejo da RDSM, instrumento de ordenação dos princípios da conservação ambiental nessa unidade de conservação. Essas orientações são feitas, em grande parte, pela intermediação dos técnicos do desenvolvimento sustentável do Instituto de Desenvolvimento Sustentável Mamirauá - IDSM e outros agentes sociais. Essas intervenções possibilitam aumento na renda familiar, diversificar e, principalmente, intensificar as atividades no trabalho familiar e comunitário e também nas relações com agentes de comercialização de outras regiões, nacionais e internacionais. Essa intensificação decorre do fato de que, ao diversificar e ampliar os produtos, a produção se faz em continuidade ao uso intensivo de força de trabalho física e familiar, com reduzidas e limitadas inovações tecnológicas para redução de tempo de trabalho, do esforço físico e de riscos de acidentes. Essas limitações decorrem em grande parte pela desestruturação neste coletivo (humanos e não humanos, conforme Callon) em relação ao uso de energia elétrica e de sistemas de abastecimento de água para as atividades econômicas e para o consumo doméstico, além de outros elementos relacionados às ações políticas como a ausência de subsídios para a produção agrícola, calendário escolar apropriado à sazonalidade da várzea, entre outras mais. Estas são questões que identificamos como elementos contraditórios às propostas de um desenvolvimento sustentável (NOBRE e AMAZONAS, 2002).

\subsubsection{ACESSO À AGUA E ENERGIA ELÉTRICA COMO DEMANDAS ESTRUTURAIS DESSE COLETIVO}

Os moradores da várzea nessa região Amazônica convivem com o paradoxo da grande quantidade de água disponível pelo seu intrincado e farto sistema fluvial mas com a precariedade de água potável e com a ausência de sua distribuição para uso nos domicílios. Por outro lado, o forte imáginário amazônico de abundância de água pela caudalosidade dos seus rios esconde da sociedade 
civil os problemas vivenciados por esses amazônidas durante os períodos da seca, com privação de água e situações de isolamento social.

Nesses povoados a água para consumo e uso doméstico ainda é retirada diretamente dos rios, assim como o faziam desde o início da ocupação deste território. Em alguns domícilios, coletam a água dos rios ou igarapés, decantam de um dia para o outro e coam em um pano para depois depositar nos potes, seguindo as orientações que receberam dos agentes de saúde comunitária da Pastoral da Criança vinculada à Prelazia de Tefé, nos anos 1980. Essa instituição religiosa também teve importante influência no gerenciamento das questões de saúde comunitária ao orientar sobre o uso de potes com pequenas torneiras para que os usuários evitassem a maior contaminação da água pelo uso direto das mãos dentro dos potes, mas essa ainda não é uma prática usual nos domicílios apesar dos mais de 30 anos de sua atuação nessas localidades, algumas vezes em parceria com agentes comunitários de saúde das prefeituras locais.

Nos meses de seca os cursos d'água em frente às comunidades, principal fonte de água para o consumo doméstico e humano, secam bastante tomando uma cor esverdeada, repleta de musgo e detritos orgânicos, de odor fétido por causa dos peixes mortos pelo forte calor da água. A água fica inapropriada para a lavagem das roupas, para o consumo, para o banho. "O cabelo da gente fica duro $e$ é puro bodó" 8 . Os moradores têm que regrar o uso da água para o consumo doméstico e humano e se organizarem para as buscas de água no interior da mata, nos olhos d'água e igarapés, "naquelas monstras distâncias", geralmente uma atividade destinada às mulheres e crianças na distribuição do trabalho doméstico. Nos meses de seca as chuvas escasseiam por dez a quinze dias. Quando chove, todas as vasilhas domésticas são usadas para aparar a água.

É recente a alternativa de armazenamento da água da chuva para beber e para os usos domésticos. E, surpreendente a atualidade dos dados dos levantamentos epidemiológicos realizados pelo IDSM, em 2005, que identificaram que há uma baixa ingestão de água por essas pessoas principalmente durante as atividades na roça quando ficam por várias horas expostos ao sol (PERES e BRUCKI, 2005). As populações convivem em ambiente de abundância de água e com muitos obstáculos e ausência de tecnologias para acesso à água potável.

Outro grande desafio estrutural às inovações científicas e tecnológicas diz respeito ao fornecimento de energia elétrica de forma contínua e eficiente para esses pequenos agrupamentos populacionais. Assim como nos séculos anteriores e em outras espaços amazônicos, na maior parte desses povoados a

8 Bodó é um peixe pequeno muito usado na alimentação cotidiana. É facilmente capturado nos igapós, rios e lagos. 
oferta da energia elétrica é feita pelas concessionárias com o uso de miniusinas a termodiesel, restrita a até quatro horas por dia e fortemente dependente das condições de entrega do diesel que geralmente é feita como um ato político das prefeituras locais. Quando a seca é rigorosa, a comunidade toda fica às escuras porque não é possível transportar o diesel da cidade. A iluminação domiciliar é completada com uso de velas, lamparinas a querosene ou a diesel com consequências perigosas à saúde dos moradores em especial das crianças e idosos.

A tecnologia das miniusinas a termodiesel é ecologicamente incorreta, com máquinas de pouca eficiência energética, operadas de forma improvisada e precária com muitos acidentes de trabalho, além de fazerem muito barulho e do desperdício de óleo inclusive com contaminação do solo (GALVÃO, et al, 2003). A falta de energia elétrica na estrutura produtiva dessas populações dificulta o uso de inovações como a conservação do pescado e outros alimentos, processamento da madeira, atividades de artesanato, e outras mais. $\mathrm{Na}$ matriz energética do governo brasileiro essas localidades são consideradas sistemas isolados e as concessionárias têm que inovar nas adequações tecnológicas ${ }^{9}$ de geração de energia para essas áreas distantes do alcance dos sistemas de distribuição convencionais.

O Programa Luz para Todos, com 12 anos de existência, se propõe a estender a iluminação elétrica a todos os domicilios brasileiros e embora já tenha levado luz elétrica a mais de 3 milhões de domicílios rurais em todo o Brasil, na área da RDSM e RDSA só atendeu até o momento algumas localidades de terra firme, próximas ao sistema de distribuição, onde é possível aplicar e estender as formas usuais de produção de energia, sem que inovações para o uso de energias alternativas tenham sido incrementadas.

Estes fatos em relação ao acesso à água potável e ao uso de energia elétrica evidenciam a grande carência de inovações sociais que possibilitem um melhor viver nesses pequenos agrupamentos populacionais da floresta alagada amazônica. Os desafios à intersecção dos diversos atores da sociedade, da ciência e da tecnologia já são antigos e se tornaram mais reconhecidos no conjunto das reivindicações por políticas sociais de maior alcance que se associaram aos movimentos socioambientais.

9 Em uma das localidades, Aiucá, está em andamento, desde 2005, um projeto de pesquisa para a análise das condições de uso de energia solar fotovoltaica em sistemas domiciliares em 24 horas de uso ininterrupto, em acordo com as normas da ANEEL. O projeto, financiado pelo CTEnerg-Cnpq e executado pelo IEE/USP e IDSM, teria um efeito disseminador a outras localidades nas mesmas condições no interior da floresta amazônica. Apesar dos resultados positivos obtidos com essa tecnologia é ainda, em 2018, a única localidade com esse tipo de investimento. 
Ao longo dos anos negociando com agencias financiadoras e com agentes de políticas públicas testemunhamos incorretas e veementes afirmações de atores institucionais de que promover acesso a bens modernos a essas populações descaracterizaria uma forma tradicional e bucólica de viver, como que condenando essas pessoas à uma condição de exclusão tecnológica, seja por sua identidade estar fortemente associada a um modo de vida com tecnologia rudimentar, seja porque se distanciam de uma relação com o mercado tecnológico uma vez que, por suas condições de baixa renda não se tornariam efetivos consumidores dos produtos dessa tecnologia.

Por outro lado, em nossa convivência com essas populações sempre testemunhamos o grande anseio desses moradores por usufruir do conforto de água na torneira dentro de casa, chuveiro no banheiro interno para evitar riscos dos banhos noturnos nos rios principalmente para os idosos, para facilitar as tarefas domésticas de cozinhar e lavar roupa, para ter água em casa para todos beberem com segurança; assim como, ter energia elétrica por 24 horas, permitindo uso de equipamentos elétricos como o freezer e a geladeira para armazenar seus alimentos e produtos diminuindo a fadiga da produção diária de alimentos, usar máquina de lavar roupa, como também fazer uso de instrumentos de trabalho, como a serra elétrica entre outras facilidades. Objetos de desejo que são descobertos com as idas mais frequentes aos centros urbanos ${ }^{10}$ e na expansão imagética da sociedade de consumo a esses rincões amazonicos pelos canais televisivos nacionais. Nos últimos 15 anos, a renda média monetária familiar se elevou, seja pelo acesso ao mercado ecológico como, principalmente, pelos programas de transferência de renda e muitas famílias se equiparam com bens de uso durável dependentes de energia elétrica (MOURA et al., 2016).

Ao discorrer sobre esses fatos, na perspectiva de uma sociologia da tradução, identificamos uma situação-problema que instiga a composição de uma rede sociotécnica com as seguintes características fundamentais: como conciliar o incremento das inovações com manutenção de uma forma de organização familiar camponesa da várzea, respeitando os arranjos e práticas socioambientais locais, com baixos custos operacionais, com facilidades de deslocamento de um lugar a outro em menos de uma geração, face às dinâmicas geomorfológicas desse ecossistema.

10 Com o aumento da renda, nos últimos dez anos, houve um enorme aumento na compra de rabetas (pequenos motores de popa para pequenas embarcações) o que deu a esses moradores uma maior mobilidade, sendo muito mais frequente a ida à cidade do que foi nas gerações anteriores. Nas comunidades mais afluentes economica como as vinculadas às atividades do ecoturismo ou da pesca manejada do pirarucu, todos os domicílios tem um motor rabeta, em algumas situações, mais de uma por moradia (MOURA et al., 2016) 


\subsection{O PROCESSO DA TRADUÇÃO}

A tradução, segundo Callon (1986, 1991, 1999), envolve quatro momentos distintos: a problematização, a atração, o envolvimento ou recrutamento e a mobilização. No momento da problematização ocorrem dois movimentos: a interdefinição dos atores e a definição de pontos de passagem obrigatórios. Os diferentes atores, ou um determinado ator, desenvolvem uma interpretação, uma hipótese sobre determinada controvérsia e procuram demonstrar que os interesses dos demais atores convergem para a problematização proposta. Neste momento é necessária a definição da identidade do problema, com seu sistema de alianças ou associações entre entidades. Para que uma determinada problematização se viabilize, o ator cria dispositivos de atração que podem ser traduzidos em eventos científicos, discursos, artigos científicos, documentos técnicos, definição das fontes de financiamento entre muitos outros. Esses dispositivos orientam a formulação de uma ou mais hipóteses de ação e se constituem um sistema de alianças em torno do protagonista da problematização. Essa atração deve ter êxito para confirmar a problematização proposta edar sequência ao processo.

A atração, por sua vez, só será bem-sucedida se a definição e a coordenação dos papéis na rede tiver resultado positivo. Esse momento da operação de tradução pode ser denominado como envolvimento ou recrutamento de atores e suas formas podem ser variadas. E, a quarta etapa é a mobilização dos aliados, quando, pela escolha de porta-vozes e ao estabelecimento de intermediários, entidades humanas e não-humanas poderão ser deslocadas e reunidas em um ponto. O processo de mobilização permite simplificar o mundo heterogêneo e complexo transformando as entidades em representantes que falam em nome dos outros. Quando uma tradução tem êxito, ela assume a configuração de uma rede. O resultado desse processo é sempre fruto de um trabalho coletivo.

Ao problematizar sobre as inovações adequadas ao uso da água e acesso à energia elétrica em pequenas comunidades da várzea amazônica, o papel do IDSM foi de ator-rede no sentido de que foi somente a partir de sua configuração como ator institucional e agenciador de um conjunto de possibilidades que tornou possível refletir sobre a várzea como parte integrante de um coletivo de humanos e não humanos com expressão peculiar da sociobiodiversidade da região amazonica. Os dispositivos de atração foram desde então traduzidos nas evidências registradas sobre esse ecossistema em eventos acadêmicos nacionais e internacionais, na circulação entre agencias governamentais e não governamentais, em diálogos com várias controvérsias que tentam convergir para a conservação da sociobiodiversidade, entre vários outros. Em um desses eventos, 
um dos técnicos do IDSM tomou conhecimento, por trajetos não planejados, da existência de placas solares fotovoltáicas que possibilitam a captação da energia solar e que com uso dessa tecnologia seria possível usar para impulsionar bombas para deslocar água de superfície dos rios para armazenamento e distribuição domiciliar. Essa se apresentou como a grande possibilidade de investimento para as comunidades de várzea. A porta de entrada para várias outras inovações. Essa tradução ocorreu pela primeira vez em 1997 e desencadeou um extenso processo de mobilização para compor uma marcante rede sociotécnica nessa trajetória institucional, que descreveremos em maior detalhe nos itens seguintes. As associações que se dão a partir de operações de tradução fundamentam a formação de uma rede sociotécnica.

Um outro aspecto ressaltado pela análise de Callon nesses caminhos da tradução é que esse processo de construção mobiliza um conjunto de técnicas e procedimentos de pesquisa de campo que constituem parte da tradição das ciências sociais, particularmente da antropologia. Por fim, as ciências sociais e humanas ao romperem com as polarizações entre sociedade / natureza, contexto / conteúdo inseriram a produção de conhecimentos sobre a ciência e a tecnologia na discussão da produção da sociedade moderna. Nessa compreensão, os atores envolvidos nos diversos processos investigativos de registros sobre o modo de vida na várzea abrem possibilidades para compreender as demandas e significados das inovações.

Ao descrevermos com recursos etnográficos uma situação problema que ressalta um conjunto de demandas por melhor viver no ambiente da várzea, colocamos em maior evidência as incertezas sobre o conhecimento desse ecossistema, como também a definição das agendas de pesquisa pelos institutos de pesquisa nacionais e locais e como operam as políticas públicas quando os sujeitos são pequenos agrupamentos populacionais, com caracteristicas ambientais e demandas muito específicas e desafiadoras tecnologicamente.

\section{A CO]MPOSIÇÃO DA REDE SOCIOTÉCNICA EM RELAÇÃO ÀS CARACTERISTICAS E DEMANDAS DAS POPULAÇÕES DA VÁRZEA DA RDSM}

Conforme Callon (1989) e seus seguidores, a rede sociotécnica compreende um conjunto de atores heterogêneos, humanos e não-humanos, associados no processo de concepção, produção e difusão de conhecimentos, dando origem a definições tecnológicas obtidas no processo de solução de controvérsias. Nesses contextos os conflitos e acordos são portas de entrada para esta investigação. 
Com uso de recursos metodológicos apropriados à apreensão dos confrontos entre os diversos interesses em jogo é possível compreender que a construção da tecnologia se torna socialmente relevante quando dialoga com o modo de produzir conhecimento diante da importância atribuída a este processo pelas instituições de ciência e tecnologia.

O senso comum nos conduz a identificar uma tecnologia apenas como uma consequência linear de decisões racionais que conduziram até a sua concretude. No entanto, quando reconstituímos a rede da qual se origina uma inovação, percebemos que o processo de desenvolvimento de tecnologias também é socialmente construído. A tradução, nessa perspectiva, expressa um processo contínuo ao longo do qual os atores se contrapõem, modificam seus interesses, definem estratégias. É, portanto, importante e necessário observar e mapear o desdobramento da rede sociotécnica que se articula entre os processos e debates tecnocientífcos e políticos na definição de novas estratégias de ação.

A partir da problematização identificada, neste artigo, analisamos a seguir os percursos na constituição de uma rede sociotécnica que teve como propósito contribuir com uma inovação social que pudesse levar água encanada aos domícilios de uma região de várzea, com uso de energia solar fotovoltáica.

No passado recente foram feitas tentativas de perfuração de poços artesianos nessa área de várzea, com a constituição de uma outra rede sociotécnica que teve como principais porta-vozes os agentes missionários da Igreja Católica nas ações da Prelazia de Tefé que, em diligência com grupos religiosos de outros países, agenciaram e financiaram a instalação dessa tecnologia de bombeamento de água. A água era obtida com uso de bombas manuais instaladas nesses poços. No entanto, seja pelo baixo nível da perfuração do poço, seja pelas características da água com muita salobridade, o uso não teve aceitação dos moradores e logo os equipamentos foram abandonados pela população. A instalação foi feita apenas em algumas comunidades católicas.

Nos últimos 20 anos, o IDSM vem implementando e aprimorando uma tecnologia social de bombeamento e abastecimento de água com uso de energia solar fotovoltáica. Para alcançar o modelo atualmente usado, esse sistema vem sendo aprimorado ao longo dos anos, na tentativa (entre acertos e erros) de encontrar o modelo mais adequado para esse ambiente. A estratégia utilizada foi instalar, inicialmente, o sistema em quatro comunidades de forma experimental para que seus resultados fossem acompanhados tanto em relação aos usos da tecnologia quanto em relação aos processos de gestão e posterior aprimoramento para expansão para as demais áreas. Foram escolhidas comunidades com: a) bom nível de organização social para garantir um bom 
suporte para a gestão do sistema; b) com características geomorfológicas diferenciadas para que fossem avaliados os níveis de pulsão da água e consequentes ajustes da tecnologia; c) foi dada preferência às comunidades situadas em limites municipais de prefeituras com maior comprometimento com essas populações para que as ações pudessem ser feitas em parceria com o poder público que, na sequência, assumiria a expansão dessa tecnologia para outras comunidades sob sua administração. No período de 2009 a 2013 foram instalados sistemas em apenas 12 das 170 localidades situadas na várzea da RDSM, o que revela a grande dificuldade de replicabilidade e expansão da inovação. As principais limitações são de natureza financeira e de gestão.

A construção da tecnologia levou em consideração, além de outros fatores operacionais, as seguintes condições : a) a sazonalidade da várzea que alterna períodos de abundância e escassez de água; b) ausência de energia elétrica de qualidade e de forma contínua; c) que trata-se de pequenos agrupamentos populacionais dispersos entre si e distantes dos principais centros comerciais da região; e d) que essas populações precisam se deslocar para outros lugares em períodos que correspondem a menos de duas gerações, em média, em virtude das frequentes alterações geomorfológicas da região.

A rede sociotécnica foi constituída por atores locais, nacionais e internacionais, estes principalmente na condição de financiadores. Grande parte desses atores ainda continua atuando nesta rede. O principal ator foi o Instituto de Engenharia Elétrica da Universidade de São Paulo IEE/USP, onde engenheiros elétricos e seus estudantes de graduação e pós graduação, fazem análises de usos e adaptações do uso das placas solares fotovoltáicas em laboratórios especializados e com interconexões com a Espanha e Alemanha. Outros atores são os pesquisadores da Universidade Federal do Pará, sendo parte deles formados por esse grupo do IEE/USP. Ainda, organizações não governamentais atuando na região amazônica, implantando sistemas de uso de energia solar fotovoltáica em comunidades indígenas; moradores e lideranças comunitárias, técnicos e agentes do desenvolvimento sustentável vinculados ao IDSM, entre outros mais. A rede possibilita, em diversas dimensões, a discussão sobre as controvérsias em relação à necessidade de barateamento do custo do sistema para que ele possa ser mantido pelos moradores das comunidades; testes com bombas de propulsão que facilitem e resistam à variedade no nível das águas dos rios e trânsito de material orgânico nesse fluxo; que tenha a maior efetividade possível durante os períodos de seca quando a população deve ficar atenta às necessidades de extensão dos tubos plásticos pelo distanciamento do rio em relação às moradias, entre outras demandas de gestão. 
O sistema é composto por placas solares fotovoltáicas, balsas flutuantes para sustentar essas placas permitindo a sua adaptação à subida e descida do nível das águas, bomba de sucção, depósitos para armazenamento da água e tubos de plastico para distribuição para as casas. A opção por uso da sucção da água de superficie foi resultado de uma observação atenta de um agente de desenvolvimento sustentável do IDSM que apresentou essa proposta após ter testemunhado o insucesso da perfuração dos poços com essa finalidade.

\section{REFLEXÕES SOBRE OS MECANISMOS DE DISPUTA E O ALCANCE DAS EXPECTATIVAS GERADAS AO LONGO DE MAIS DE 20 ANOS DE USO DESSA INOVAÇÃO.}

A primeira iniciativa relacionada a essa tecnologia na região Amazônica foi implantada pelo Programa de Desenvolvimento Energético dos Estados e Municípios (Prodeem), um programa do Governo Federal instituído em 1994 para atender às localidades isoladas não supridas de energia elétrica pela rede convencional, obtendo essa energia de fontes renováveis locais. O IEE/USP participou deste programa inicial e em conjunto com a equipe técnica do IDSM propôs um projeto experimental que foi financiado com recursos desse programa.

O modelo experimental foi sendo readaptado, redimensionado e os moradores das comunidades, que nunca tinham ouvido falar sobre as potencialidades energéticas do sol, foram aos poucos se acostumando com essas placas, interpretando as suas formas de uso, aprendendo a administrar os cuidados com o equipamento que requer proteção dos animais que transitam nas comunidades, como jacarés e bois, fazendo a limpeza das placas para melhorar sua capacidade de armazenamento de energia, entre outros aprendizados.

Os principais problemas identificados no sistema estão relacionados ao processo de sucção da água do rio para o reservatório. O modelo de bomba utilizado atualmente é importado, de alto custo, em média $\mathrm{R} \$ 8$ mil reais, e tem se demonstado como um tipo de bomba de difícil manutenção. Portanto, o maior desafio, desde a primeira implementação até os dias atuais, é encontrar uma bomba adequada às características físicas do ambiente, ou seja, com alto recalque e alta vazão, além de suportar a grande concentração de sedimentos (barro) da água dos rios.

A bomba utilizada na primeira instalação, com recursos do PRODEEM, foi um modelo importado chamado McDonald que não apresentou o desempenho desejado em termos de vazão e recalque, mas que ainda teve uma vida útil de 5 anos. Entretanto, segundo o técnico do IDSM responsável pelo 
aocmpanhamento desses experimentos, este modelo de bomba, devido à sua rusticidade tecnológica suportou bem as caracteristicas dessa água de rio com grande presença de sedimentos.

O modelo utilizado na segunda instalação também foi importado, da marca Grunfos, considerada uma tecnologia mais avançada com alta vazão e recalque, ideal para atender a demanda de água nos domicílios. Entretanto, essa marca se mostrou mais sensível às características da água da região, registrando uma vida útil de menos de 3 anos. Outro problema verificado com os primeiros equipamentos instalados, que chamou atenção dos representantes comerciais da marca e de pesquisadores do Laboratório do IEE/USP foi a oxidação do material externo que reveste a bomba. Os técnicos atribuíram a corrosão ao alto $\mathrm{PH}$ da água barrenta do rio Solimões. Mesmo depois de procurados insistentemente pelos técnicos do IDSM, os representantes dessa marca no Brasil não deram retorno sobre as possíveis soluções para a falha.

Esse modelo de bomba é o que Akrich et al. (1988) chamam de modelos rígidos, para os quais os fabricantes não estão dispostos a questionar o design, onde não existe flexibilidade tecnológica que permita uma adaptação com bricolagem. As tecnologias estabelecidas no mercado possuem o princípio de "pegar ou largar" (AKRICH et al.,1988)

Segundo um dos técnicos do IDSM, esse modelo de bomba apresenta duas dificuldades que precisam ser superadas para viabilizar o sistema de bombeamento de água do rio com energia solar fotovoltaica: a primeira está relacionada à complexidade da tecnologia, que não permite o conserto fora das oficinas autorizadas da marca, inviabilizando a autonomia e a gestão dos problemas pelas famílias; e a segunda está relacionada ao preço da bomba no mercado nacional - em 2016, custava em torno de $\mathrm{R} \$ 8$ mil reais, e disponível apenas nas grandes capitais do país.

Essas condições dificultam o processo de construção social da tecnologia por parte das famílias usuárias dos sistemas, principalmente pela restrição do mercado e pelo baixo domínio cognitivo sobre a mesma. Portanto, o sistema almejado exige um tipo de equipamento que seja robusto no bombeamento, facilmente encontrável no mercado, que tenha valores praticados no contexto local e cuja tecnologia permita a sua manutenção (bricolagem) localmente e de forma menos corporativa.

Uma outra alternativa, iniciada em 2010, desenvolvida por essa rede sociotécnica foi um sistema híbrido de armazenamento de água, instalando junto ao sistema uma cisterna com capacidade de armazenar 25 mil litros de água da chuva. As famílias tinham o hábito de armazenar água da chuva em 
pequenos recipientes, como baldes, potes e garrafas PETs. A ideia de testar esse modelo híbrido surgiu depois de entrevistadas as famílias, que informaram que a quantidade estocada em casa não era suficiente para atender os períodos de maior estiagem, e que com um depósito maior poderiam resolver o problema do armazenamento de água.

Entretanto, esse modelo não se mostrou eficiente por duas razões: a primeira, pelo curto tempo que chegou a ser usado pelas famílias - cerca de dois anos -, pois um incêndio afetou o equipamento, não dando tempo para que tecnologia fosse apropriada pela comunidade; a segunda razão se deveu à dificuldade de implementar o projeto coletivo para o uso do sistema, que exige a organização da comunidade para esse uso. Em entrevistas, 55\% das famílias declararam preferir captar a água da chuva, pois conseguem fazer o manejo do recurso de forma mais autonoma.

A implementação dos sistemas de bombeamento de água de superfície é feito de forma participativa. As tarefas são divididas entre os técnicos do IDSM e as famílias da comunidade que estão recebendo a tecnologia. As etapas seguem um procedimento orientado pelos agentes externos, de acordo com a especialidade de cada grupo. Os técnicos ficam responsáveis pela instalação e capacitação, e às famílias cabem as tarefas de extração da madeira para construir as bases de sustentação das placas fotovoltaicas e do reservatório, e de instalação da rede de distribuição de água para os domicílios. Após a instalação, os técnicos do IDSM realizam capacitações para os usuários. Essas capacitações são importantes para o processo de apropriação e empoderamento das famílias na gestão dessa nova tecnologia introduzida no seu cotidiano. Exemplo disso ocorre no período da seca, quando o distanciamento do rio exige que os moradores se organizem para estender também a tubulação; ou quando novas casas são construídas e o grupo familiar que chega precisa negociar a ampliação do sistema até sua casa.

A orientação inicial dada pelos técnicos para a composição do grupo responsável pela gestão do sistema é que este seja composto por dois homens e uma mulher. No primeiro momento, as famílias costumam seguir a orientação, entretanto, os responsáveis pelo sistema logo começam a se defrontar com a sobrecarga de atividades e com a criação de uma situação de dependência da comunidade para com o grupo gestor. A partir dos enfrentamentos travados na gestão comunitária, os moradores vão encontrando formas alternativas para minimizar os efeitos negativos da introdução da tecnologia, adotando estratégias de revezamento semanal ou mensal entre os responsáveis pela manutenção da mesma.

O funcionamento do sistema exige dos gestores um esforço diário e na falta de um responsável a comunidade toda ficará sem água ou energia. O 
funcionamento do sistema de água é contínuo, somente interrompido quando ocorre uma grande cheia. Nesse período, que dura em torno de dois a três meses, a bomba é desligada, pois o terreno enxarcado amolece, correndo risco de não suportar o peso da caixa d'água, cuja capacidade média é de 10 mil de litros. Um dilema enfrentado pelas famílias é o de encontrar a melhor forma de gestão compartilhada, sem comprometer as múltiplas atividades já desempenhadas no dia a dia pelos grupos e nem o funcionamento dos serviços básicos e essenciais.

Quadro 1 - Características da organização política e nível de mobilização em comunidades com sistema de bombeamento de água.

\begin{tabular}{|c|c|}
\hline $\begin{array}{l}\text { Comunida- } \\
\text { des com me- } \\
\text { nor nível de } \\
\text { mobilização }\end{array}$ & $\begin{array}{l}\text { Os trabalhos são concentrados em um pequeno grupo eleito; } \\
\text { Os gestores não conseguem articular a comunidade para partilhar os } \\
\text { trabalhos; } \\
\text { Os gestores geralmente moram próximo ao sistema ou assumem uma } \\
\text { função de liderança e acumulam atividades; } \\
\text { Não há um revezamento ou nova eleição para seleção de novos } \\
\text { responsáveis pelo funcionamento do sistema; } \\
\text { Não há uma mobilização por parte dos eleitos para articular nova } \\
\text { eleição, o que pode estar relacionado à falta de interesse da comunidade, } \\
\text { ou a disposição dos eleitos em continuar assumindo a função, de forma } \\
\text { a concentrar um poder legítimo perante o grupo; } \\
\text { O sistema funciona com maior interrupção, por depender } \\
\text { exclusivamente de poucas pessoas; } \\
\text { Não há um conhecimento geral das famílias sobre quem são os } \\
\text { responsáveis pela gestão do sistema; } \\
\text { Pouca disposição para pagar pelo uso da água encanada e pela taxa de } \\
\text { manutenção; } \\
\text { Postura de sempre esperar por integrantes do IDSM para resolver os } \\
\text { problemas técnicos do sistema. }\end{array}$ \\
\hline $\begin{array}{l}\text { Comuni- } \\
\text { dades com } \\
\text { maior nível } \\
\text { de mobili- } \\
\text { zação }\end{array}$ & $\begin{array}{l}\text { Após a instalação seguem a orientação recebida pelos técnicos do } \\
\text { IDSM em eleger três representantes; } \\
\text { Identificam a dificuldade de depender de poucas pessoas e testam outras } \\
\text { formas de compartilhar o trabalho para garantir o funcionamento do } \\
\text { sistema; } \\
\text { Articulam a indicação de novos membros e formas alternativas de } \\
\text { gestão com a comunidade; } \\
\text { Aumentam o número de eleitos; } \\
\text { Fazem revezamento semanal ou mensal por família; } \\
\text { Controlam mais eficiente sobre o funcionamento do sistema por parte } \\
\text { da comunidade; } \\
\text { Reagem de forma positiva ao desafio de criar um fundo de reserva } \\
\text { para eventuais problemas técnicos com o sistema; } \\
\text { Procuram os técnicos do IDSM quando há alguma dificuldade com o } \\
\text { sistema de água. }\end{array}$ \\
\hline
\end{tabular}


Em seus depoimentos as famílias relatam os efeitos da introdução desse sistema no dia a dia da comunidade. Os principais relatos referem-se à diminuição do esforço físico no trabalho doméstico, geralmente desempenhado por mulheres e crianças. Mas também dizem respeito à menor exposição ao sol; à redução do risco de acidentes por afogamento com crianças que sempre acompanham as mães nas tarefas de lavar roupa à beira do rio; possibilidade da privacidade na higiene pessoal; facilidade nas atividades produtivas, como na limpeza do pescado; diminuição de doenças diarreicas e de suas consequências, como a anemia, desidratação, desnutrição e óbitos, principalmente das crianças.

Os depoimentos abaixo sobre os usos sociais do sistema de água, ressalta os benefícios à vida das famílias ao longo desses anos.

- Antes nós tínhamos que ir na beira carregar água, lavar roupa - bacia de louças pesada. E no período da seca a água fica muito longe. E tinha que carregar água três vezes por dia. Hoje com água dentro de casa, parece que tudo é fácil, tudo é feliz. Os homens já estão fazendo as casas com o banheiro dentro, com chuveiro, para seus filhos e esposa. Muita mulher diz que se o sistema esculhambar, vai embora para a cidade. (L.M.S, 28 anos).

- A gente sofre muito no período da seca. Tem seca que quando chega no barro de louça faz. um barraco de 16 degraus, quando ia pegar água na volta eu chegava quase morta dentro de casa. Uma vez, meu filho foi pegar água lá em baixo e quando chegou no último degrau o balde virou para trás e caiu, quebrou balde, perdeu a água e quase acontece um acidente e perco meu filho. Tinha momento que dava vontade de chorar, quando olhava para o barranco e via a escadaria. Agora não, tá todo mundo feliz. (R.C.S, 39 anos). Outubro/2015

Serpa (2001) identificou na experiência em Lagamar com famílias caiçaras, no interior do estado de São Paulo, que a construção coletiva do projeto de bombeamento exige um papel preponderante e participativo das mulheres desde as discussões iniciais, e que é fundamental a valorização do papel feminino no contexto do sistema energético local. Na divisão sexual do trabalho, como é registrado em outros grupos tradicionais, cabe às mulheres um papel importante na manutenção do sistema energético, com sua participação nas roças e no processamento dos produtos, no provimento de água para consumo, e nos cuidados da casa e dos filhos. (SERPA, 2001, p. 174).

Essa divisão apresentada por Serpa se assemelha à forma como as famílias ribeirinhas se organizam e dividem os trabalhos diários. Portanto, o envolvimento das mulheres em todo o processo garante a sustentabilidade da tecnologia social, 
tendo como sustentação a organização dos usuários e a efetiva participação das mulheres nas atividades e nas tomadas de decisões. Akrich et al. (1988) reforçam que para alcançar o sucesso de inovação é importante considerar a escolha de representantes ou porta-vozes que irão interagir, negociar, moldar o projeto e transformá-lo, seria um porte parole légitime no sentido de representar a comunidade em determinados espaços que possam atrair outros atores para compor a rede.

\section{CONSIDERAÇÕES FINAIS}

O estudo possibilita refletir sobre o processo de desenvolvimento de tecnologias como socialmente construído, e no caso específico, como as inovações são afetadas pelas políticas nacionais de ciência e tecnologia, na medida em que, no seio de uma sociedade capitalista, esse desenvolvimento sofre as pressões do direcionamento das pesquisas para o desenvolvimento de tecnologias economicamente competitivas que podem realimentar e manter o mercado tecnológico.

Os dados apresentados a partir da tradução de uma situação de demandas de sociedades de organização camponesa, com reduzida composição demográfica e habitantes de uma área de floresta alagada, instigam a reavaliar os princípios constitutivos da ciência e tecnologias modernas no sentido de estimular a criação de inovações tecnológicas que, distanciadas das prioridades da sociedade de consumo possam contribuir com o bem viver dessas populações.

\section{REFERÊNCIAS}

ALENCAR, E. F. Memórias de Mamirauá. Tefé. Am. Instituto de Desenvolvimento Sustentável Mamirauá. 2010.

ALENCAR, Edna Ferreira. Terra Caída: Encante, Lugares e Identidades. 262 f. Tese (Doutorado em Antropologia) - Departamento de Antropologia, Universidade de Brasília - UNB, Brasília, 2002.

AKRICH, M., CALLON, M. et LATOUR B., 1988, A quoi tient le succès des innovations? 1 : L'art de l'intéressement, Gérer et comprendre, Annales des Mines, 11, 1988: p. 4-17. 
AYRES, J. M. As matas de várzea do Mamirauá: Médio Rio Solimões. Brasília: CNPq, Sociedade Civil Mamirauá, 1993. (Estudos Mamirauá, 1).

BAUMGARTEN, M. Sociedade e Sustentabilidade: qual o lugar do conhecimento?. Sociologias, Porto Alegre, ano 16, n. 37, set/dez, p. 14-22. http://dx.doi.org/10.1590/15174522-016003701. 2014.

BIJKER, W. E. Of bicycles, bakelites, and bulbs: toward a theory of sociotechnical change. Massachusetts: The MIT Press, 1995.

BLOOR, D. Conocimiento e imaginario social. Barcelona: Gedisa, 1998.

BRANDÃO, F. C. Programa de Apoio às Tecnologias Apropriadas - PTA: avaliação de um programa de desenvolvimento tecnológico induzido pelo CNPq. Dissertação (mestrado em desenvolvimento sustentável) - UnB, Brasília, 2001.

CALLON, M Le réseau comme forme emergente et comme modalité de coordination: le cas des interactions stratégiques entre firmes industrielles et laboratoires académiques. In: CALLON, M. Et al. Réseau et coordination. Paris: Economica.1999. p.13-64.

CALLON, M Réseaux technico-économiques et irréversibilité. In: BOYER, R.; CHAVANCE, B.; GODARD, O (eds). Les figures de 1'irréversibilité en économie. Paris: Editions de L'École des Hautes Études en Sciences Sociales, 1991. p. 194-230.

CALLON, M. Society in the making: the study of technology as a tool for sociological analysis. In: BIJKER, W. E. et al. (Ed). Social construction of technological systems. Cambridge: Cambridge University Press, 1987.

CALLON, M. Some elements of a sociology of translation: domestication of the scallops and the fishermen of St Brieuc Bay. In: Law, J. (Ed). Power, Action and Belief: a new sociology of knowledge? Sociological Review Monograph 32. London: Routledge and Kegan Paul. 1986 p. 196-233.

CALLON, M. "Struggles and Negociations to Define What Is Problematic and What Is Not: the Socio-Logics of Translation", In: KNORR, K. D., KROHN, R. e WHITLEY, R. (Eds.), The Social Process of Scientific Investigation, Dordrecht: D. Reidel. 1980. p. 197-219, 1980.

CALLON, M. Por uma nova abordagem da ciência, da inovação e do mercado. IN: PARENTE, A. (Ed.) A trama da rede. Porto Alegre: Sulina, 2004. 
CALLON, M; LASCOUMES, P. e BARTHE, Y. Agir dans un monde incertain: essai sur la démocratie technique. Paris: Éditions du Seuil, 2001.

DAGNINO, R. Tecnologia apropriada: uma alternativa? Dissertação (mestrado) - UnB, Departamento de Economia, Brasília, 1976.

DAGNINO, R. Enfoques sobre a relação ciência, tecnologia e sociedade: neutralidade e determinismo. In: Organização dos Estados Iberoamericanos para a Educação, a Ciência e a Cultura. Sala de Lectura CTS+I de la OEI, 2002b. Disponível em: < http://www.campusoei.org/salactsi/index.html

DAGNINO, R. A relação universidade-empresa no Brasil e o "argumento da hélice tripla". Revista Brasileira de Inovação, Rio de Janeiro, Finep, v. 2, n. 2, p. 267-308, jul./dez. 2003.

DAGNINO, R.; BRANDÃO, F.C. e NOVAES, H.T. Sobre o marco analítico conceitual da tecnologia social. In: Tecnologia Social - uma estratégia para o desenvolvimento. Rio de Janeiro, Fundação Banco do Brasil, 2004.

DAGNINO, R., NOVAES, Henrique T., A Adequação Sócio-Técnica na agenda do Complexo de C\&T e dos Empreendimentos autogestionários. XI Seminário Latino-Iberoamericano de Gestion Tecnológica. 25 a 28 de outubro/2005. Salvador. Brasil.

DICKSON, D. Tecnología alternativa y políticas del cambio tecnológico. Madri: H. Blume, 1978.

GALVÃO, Luiz Cláudio Ribeiro, UDAETA, Miguel Edgard Morales, PAZZINI, Luis Henrique Alves, GIMENEZ, André Luis Veiga e NISHIMARU, Rodrigo Shinji. Relatório de Visita Técnica à Reserva de Desenvolvimento Sustentável Mamirauá. Grupo de Energia do Departamento de Engenharia de Energia e Automação Elétricas da Escola Politécnica da Universidade de São Paulo.São Paulo; GEPEA, 2003.

GIDDENS, Anthony. Modernização Reflexiva. São Paulo: UNESP. 2002.

JUNK, Wolfang J.,The Central Amazon river floodplain: concepts for the sustainable use of its resources. IN: JUNK, Wolfang J.; OHLY J.J.; PIEDADE, M.T. F; e SOARES, M.G.M. (ed.) The Central Amazon Floodplain: Actual Use and Options for a Sustainable Magagement. Leiden: Bachhuys Publishers, Netherlands, 2000: 75-94. 
LATOUR, B. Ciência em ação: como seguir cientistas e engenheiros sociedade afora. Tradução de Ivone C. Benedettí; revisão de tradução Jesus de Pauta Assis. São Paulo. Editora UNESP, 2000.

LATOUR, B. A Esperança de Pandora: ensaios sobre a realidade dos estudos científicos. São Paulo: EDUSC, 2001.

LATOUR, B. Where are the missing masses? The sociology of a few mundane artifacts. In: BIJKER, W.; LAW, J. (Ed.) Shaping technology/building society. Cambridge: The MIT Press, 1992.

LIMA, D. de M. (Org.) Diversidade socioambiental nas várzeas dos rios Amazonas e Solimões: perspectivas para o desenvolvimento da sustentabilidade. Manaus: Provárzea/MMA/IBAMA/PPG7, 2004.

LIMA, D. de M e ALENCAR, E. F. Histórico da ocupação humana e mobilidade geográfica de assentamentos na várzea do médio Solimões. In: TORRES, Haroldo; COSTA, Heloisa. (Orgs.). População e Meio Ambiente: debates e desafios. São Paulo: Senac, 2000: p.133-161.

MACHADO, C.J.S, e TEIXEIRA, M. O. A inovação para a sociologia da Tradução. Revista de Antropología Iberoamericana, Ed. Electrónica Núm. Especial. Noviembre-Diciembre 2005 Madrid: Antropólogos Iberoamericanos en Red. ISSN: 1578-9705.

MOURA, E. A. F. Práticas socioambientais na Reserva de Desenvolvimento Sustentável Mamirauá. Tese (Doutorado em Desenvolvimento Sustentável do Trópico Úmido) - Núcleo de Altos Estudos Amazônicos, Universidade Federal do Pará, Belém, 2007.

MOURA, E.; NASCIMENTO, A.C.S ; CORREA, D. S.; ALENCAR, E; SOUSA, I. S.; Sociodemografia da Reserva de Desenvolvimento Sustentável Mamirauá: 2001- 2011 / Tefé, AM: Instituto de Desenvolvimento Sustentável Mamirauá; Belém: IDSM; NAEA; 2016.

NASCIMENTO, A. C. S. do., Tecnologia social para qualidade de vida em territórios de conservação. (Tese de Doutorado em Ciências Sociais Sociologia) - Instituto de Filosofia e Ciências Humanas - IFCH. Programa de Pós-Graduação em Ciências Sociais- PPGCS, Belém. 2017. 
NOBRE, M. e AMAZONAS, M. C. (Ed.) Desenvolvimento Sustentável: a institucionalização de um conceito. Brasília: IBAMA, 2002.

PERES, L. V. C.; BRUCKI, S. M. D. Condições de saúde e de acesso aos serviços públicos de saúde das comunidades ribeirinhas do Mamirauá e Amanã - IDSM. Relatório de pesquisa. Tefé: IDSM, 2005.

PORRO, Antonio. O povo das águas. Ensaios de etno-história amazônica. Rio de Janeiro: Vozes, 1995.

SERPA, P. M. N. Eletrificação fotovoltaica em comunidades caiçaras e seus impactos socioculturais. 252p. Tese (Doutorado) - Programa Interunidades de Pós-graduação em Energia da Universidade de São Paulo. 2001.

SNUC, Sistema Nacional de Unidades de Conservação da Natureza - lei n ${ }^{\circ}$ 9.985, de 18 de julho de 2000; decreto no 4.340, de 22 de agosto de 2002. $5^{\text {a }}$ ed. aum. Brasília: MMA/SBF.

TEISSERENC, M. J. da S. A.; SANT'ANA JÚNIOR, H. A. de; ESTERCI, N. (Ed.) . Territórios, mobilizações e conservação socioambiental. São Luís: EDUFMA, 2016.

THOMAS, H. E. Tecnologias para Inclusão Social e Políticas Públicas na América Latina. In: OTTERLOO, Aldalice. Tecnologias Sociais: caminhos para a sustentabilidade. Brasília, DF. 2009.

VARANDA, A. P. de M. e BOCAYUVA, P. C. C. Tecnologia Social, Autogestão e Economia Solidária. Rio de Janeiro : FASE | Ippur | Lastro | UFRJ, 2009.

VERCELLI, A. Reconsiderando las tecnologías sociales como bienes comunes. ÍCONOS, Revista de Ciencias Sociales de FLACSO Ecuador. CONICET de Argentina. 2009. 
